\title{
Improving infant sleep safety via electronic health record communication: a randomized controlled trial
}

\author{
Ethan A. Canty ${ }^{1}$, Benjamin N. Fogel ${ }^{2}$, Erich K. Batra ${ }^{2,3}$, Eric W. Schaefer ${ }^{4}$, Jessica S. Beiler ${ }^{2}$ and lan M. Paul ${ }^{2,4^{*}}$ (D)
}

\begin{abstract}
Background: With increased use of telehealth, interventions to improve infant sleep environments have not been explored. This study sought to assess the feasibility and efficacy of using electronic health record patient portals to transmit photographs of infant sleep between mothers and healthcare professionals as part of an intervention to promote sleep environments consistent with AAP guidelines.
\end{abstract}

Methods: One hundred eighty-four mother-newborn dyads consented to participate in a randomized trial requiring patient portal registration within 1 month of delivery. We first assessed feasibility as measured by a) the proportion of consented mothers enrolling in the portal and b) maternal adherence to prompts to submit photographs of their infant sleeping to the research team through the patient portal. Intervention group mothers were prompted at 1 and 2 months; controls were prompted only at 2 months. Efficacy was determined via research assistant review of submitted photographs. These assistants were trained to detect sudden unexplained infant death risk factors utilizing AAP guidelines. Standardized feedback was returned to mothers through the patient portal. We used Fisher's Exact test to assess group differences in guideline adherence at 2 months.

Results: One hundred nine mothers (59\%) enrolled in the patient portal and were randomized to intervention $(N=55)$ and control ( $N=54)$ groups. 21 (38, 95\% Cl 25-52\%) intervention group participants sent photographs at 1 month and received personalized feedback. Across both groups at 2 months, 40 (37, 95\% Cl 28-46\%) sent photographs; 56\% of intervention group participants who submitted photographs met all safe sleep criteria compared with $46 \%$ of controls (difference 0.10 , $95 \% \mathrm{Cl}-0.26$ to $0.46, p=.75$ ). Common reasons for guideline non-adherence were sleeping in a room without a caregiver (43\%), loose bedding (15\%) and objects (8\%) on the sleep surface.

Conclusions: Utilizing the patient portal to individualize safe infant sleep is possible, however, we encountered numerous barriers in this trial to assess its effects on promoting safe infant sleep. Photographs of infants sleeping showed substantial non-adherence to AAP guidelines, suggesting further needs for improvement to promote safe infant sleep practices.

Trial registration: Name: Improving Infant Sleep Safety With the Electronic Health Record; Clinicaltrials.gov: NCT03662048; Date of Registration: September 7, 2018;

Data Sharing Statement: None

Keywords: SIDS, SUID, HER, Electronic health record, Patient portals, Photograph

\footnotetext{
* Correspondence: ipaul@psu.edu

${ }^{2}$ Department of Pediatrics, Penn State College of Medicine, HS83, 500

University Drive, Hershey, PA 17033, USA

${ }^{4}$ Public Health Sciences, Penn State College of Medicine, Hershey, PA, USA

Full list of author information is available at the end of the article
}

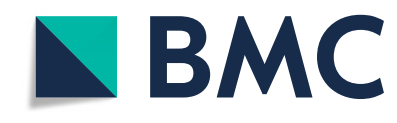

(c) The Author(s). 2020, corrected publication 2020. Open Access This article is licensed under a Creative Commons Attribution 4.0 International License, which permits use, sharing, adaptation, distribution and reproduction in any medium or format, as long as you give appropriate credit to the original author(s) and the source, provide a link to the Creative Commons licence, and indicate if changes were made. The images or other third party material in this article are included in the article's Creative Commons licence, unless indicated otherwise in a credit line to the material. If material is not included in the article's Creative Commons licence and your intended use is not permitted by statutory regulation or exceeds the permitted use, you will need to obtain permission directly from the copyright holder. To view a copy of this licence, visit http://creativecommons.org/ licenses/by/4.0/. The Creative Commons Public Domain Dedication waiver (http://creativecommons.org/publicdomain/zero/1. 0/) applies to the data made available in this article, unless otherwise stated in a credit line to the data. 


\section{Background}

Sudden Infant Death Syndrome (SIDS) rates decreased substantially between the years 1983-2012, associated with public health campaigns like "Back to Sleep" [1]. Nonetheless over 3000 deaths still occur annually due to Sudden Unexpected Infant Deaths (SUID), a term that includes SIDS of unknown cause or accidental suffocation and strangulation in bed [2].

The majority of SUIDs occur in infants between the ages of one and 4 months, and $90 \%$ of all SUIDs occur prior to the age of 6 months [3]. Therefore, optimizing sleep environments from early infancy remains the best practice for preventing SUIDs [4-6]. Adherence to SUID prevention recommendations is generally lower among lower income, less educated, and minority families [7-12]. Unfortunately, adherence is generally also poor in wealthier populations. A recent study demonstrated that even when such mothers knew they are under video observation, they commonly fail to adhere to American Academy of Pediatrics (AAP)-endorsed infant sleep recommendations [13]. Similar findings were recently reported in Australia [14]. This suggests either a knowledge gap about recommendations, an inability to comply with them, or a lack of belief that the risk is significant for their child.

Mobile health interventions and messaging to mothers of infants have shown some success in improving supine infant sleep rates and avoiding soft bedding use, suggesting technology and social media may be a possible intervention for improving infant sleep safety $[15,16]$. Use of patient portals, secure online websites that give families convenient access to electronic health record (EHR)based personal health information from anywhere with an Internet connection, has become widespread in healthcare $[17,18]$, with research showing that transmission of wound photographs via the patient portal to be an acceptable alternative to in-person general surgery care [19]. Furthermore, use of patient portals has been shown to improve patient access to information, insight into clinical conditions and health, patient communication and continuity of care, and preventive health delivery $[20,21]$. Recognizing its potential to deliver preventive guidance for SUID, we conducted a randomized clinical trial designed to test the feasibility and efficacy of using the patient portal to reduce unsafe infant sleep practices and improve adherence to the AAP SIDS guidelines [5]. For feasibility, we aimed to see if mothers would register for patient portal use during the newborn period and then send photographs of their infant sleeping when prompted. For intervention efficacy, we sought to evaluate whether provision of safe sleep feedback in response to transmitted photographs at infant age 1 month was associated with greater safe sleep guideline adherence at 2 months compared with those receiving no guidance at 1 month.

\section{Methods}

\section{Participants}

Mothers and their term newborns were recruited in person by research staff from a single maternity ward (Penn State Milton S. Hershey Medical Center, Hershey, Pennsylvania, USA) before hospital discharge. In obtaining informed consent, mothers were informed that the primary purpose of the study was "to see if we can use the patient portal to provide more individualized healthcare for you and your baby, and the way we are trying to test this idea is to see if we can use the patient portal to more personalize safe infant sleep care." All mothers with newborns at this center receive information on SIDS prevention and education on safe sleep during their stay on the maternity unit using Pennsylvania Department of Health approved printed materials, and safe sleep is modeled by providers throughout the stay. In addition, mothers are directed to sign an acknowledgement statement that they have received, read and understand the educational materials per Pennsylvania's Sudden Infant Death Syndrome Education and Prevention Act [22].

Enrollment began in October 2018 and was completed in June 2019. To be eligible for the study, infants needed to be $\geq 37$ weeks' gestation and singleton with planned follow-up at a Penn State Health practice for primary care visits. Additionally, only English-speaking mothers $\geq 18$ years old with full email and internet access were eligible. Finally, to participate, mothers were required to have an electronic device that can take photographs to be transmitted through the online patient portal, which they agreed to access.

During enrollment, mothers had two options to enroll their newborn in the patient portal following local health system procedures. The first option required them to complete a form. One of the researchers faxed the form to the patient portal office, and the mother then would receive an email with a link to enroll their newborn in the patient portal. In the second option, mothers could enroll by either calling the patient portal office while in the hospital or when at their newborn's outpatient visit. Mothers were given the phone number of the patient portal office if they decided to call to enroll.

The Penn State Health Patient Portal user interface allows parents to view their child's health data. Parents, at the minimum, can view provider summaries from each visit, lab results, vaccinations, and vital signs. The patient portal also has a messaging service whereby parents may select the provider to send an e-message. The patient portal allows attachments to be sent, including images, between providers and portal users. While not fully utilized for this purpose today, the portal is capable of supporting two-way information sharing and communication between providers and families that could be used for health promotion. 
The Human Subjects Protection Office of the Penn State College of Medicine approved this study and it was registered at http://www.clinicaltrials.gov prior to first participant's enrollment (NCT03662048). The study adheres to CONSORT guidelines.

\section{Randomization and study groups}

After consenting to the study and being provided with information on how to register for the patient portal, mothers were encouraged to create a patient portal account for their infant within a month of delivery. Participants were given one reminder call and email per week encouraging them to enroll by the 1 month deadline in order to continue in the study. Even if a parent had at least one child with a Penn State Patient Portal, parents were required to register their newborn for a patient portal via a link sent by email, as described above. Randomization occurred after an account was created, was stratified by parity at the time of delivery $(0$ vs. $\geq 1)$ with a 1:1 allocation ratio, and was performed using REDCap software. Participants who did not enroll in the patient portal within a month were considered lost-tofollow-up and were not randomized.

Following randomization, at 1 month, intervention group mothers were sent a message through the patient portal with instructions on how to take two photographs of their infant sleeping on each of their nighttime sleep surfaces and how to send the photographs through the portal to the research team. Participants were asked to take two photographs from two different angles to capture the entire sleep surface. Participants received a reminder message to transmit the photographs each week until 2 weeks after the initial message or the photographs were received. The photographs were analyzed by trained research assistants (EAC and JSB) following training by a content expert (EKB) based on a checklist of risk factors for SUID described in the AAP guidelines (Table 1). Inter-rater reliability had been planned, but because study recruitment difficulties resulted in a lower than expected sample size, we determined that this was unlikely to affect study outcomes. Personalized feedback based on standardized scripts from the checklist was generated by the study team detailing AAP recommendations and sent to the mothers through the patient portal within 7 business days. This feedback detailed which features of the infant sleep environment were adherent to the AAP guidelines as well as corrective guidance for features that were non-adherent. Controls were not contacted at 1 month. At infant age 2 months, mothers in both study groups were asked to submit photographs, and identical procedures were followed as described above for the intervention group at 1 month. All infants were expected to receive standard health maintenance visits with their primary care provider, and guidance given as part of this study was only meant to supplement usual care.

\section{Measures \\ Demographics and baseline data}

We collected data regarding the pregnancy, delivery, and nursery course for each mother and newborn from the medical record. Family demographic information was collected via survey during enrollment.

\section{Determination of final outcomes based on AAP criteria}

Using the checklist in Table 1, we determined whether an infant met all of the AAP recommendations for sleeping environments at 1 and 2 months. For any item on the checklist that could not be assessed, we elected to not presume the infant was placed in an at-risk environment. Sleep room location was determined via subjective parental reporting when photographs were transmitted.

\section{Sample size and analysis plan}

The primary outcome for this study was the proportion of participants at 2 months who were classified as meeting all of the safe sleep criteria based upon AAP guidelines [5]. Based upon AAP guideline adherence found in our prior research [13], we anticipated that $50 \%$ of controls would have identifiable SUID risk factors on the submitted photographs compared with $25 \%$ from the intervention group. A total of 57 mother-infant dyads in each randomized group yielded $80 \%$ power to detect that difference for a test conducted at the $5 \%$ level of significance. To account for potential attrition after randomization, we planned to enroll an additional 16 dyads for a total sample size of 130 . For the primary outcome of proportion meeting AAP safe sleep criteria at 2 months, we used a two-sided Fisher's Exact test conducted at the $5 \%$ level of significance to test for statistically significant differences between randomized groups.

A secondary outcome, which assessed the feasibility of the study, was defined as the proportion of patients who provided photographs through the patient portal. The proportions providing photographs were calculated for the intervention group only at 1 month; proportions were calculated for both groups combined at 2 months since we expected no difference in adherence to photograph requests between groups. We calculated $95 \%$ confidence intervals (CIs) for these proportions using the exact binomial method.

\section{Results}

Among 187 participants who provided written informed consent, 184 (98\%) mother-newborn dyads met all inclusion criteria and were asked to register their newborn 
Table 1 SUID risk factor checklist used to evaluate photographs

\begin{tabular}{ll}
\hline Unsafe sleep risk identified in infant's photograph & Infant sleep consistent with AAP guidelines \\
\hline$\square$ Not sleeping on own sleep surface & $\square$ Sleeping on own sleep surface \\
$\square$ Not sleeping on back & $\square$ Sleeping on back \\
$\square$ Soft sleep surface & $\square$ Firm sleep surface \\
$\square$ Soft object in sleep area & $\square$ No loose objects in sleep area \\
$\square$ Pillow & \\
$\square$ Stuffed animals or toys & \\
$\square$ Other loose objects in sleep area: & $\square$ No loose bedding in sleep area \\
$\square$ Loose bedding in sleep area & $\square$ No dangling cords or electrical wires in sleep area \\
$\square$ Dangling cords or electrical wires in sleep area & $\square$ Sleeping in crib, bassinette, portable crib, or play yard \\
$\square$ Sleeping in car seat, stroller, swing, carrier, sling, or other & \\
$\square$ Sleeping on couch, armchair \\
$\square$ Sleeping on bed designed for an adult or older child \\
$\square$ Bumper pads attached to crib slats \\
$\square$ Sleep wedge/positioner on sleep surface \\
$\square$ Covering of the face and head & $\square$ No bumper pads \\
\hline
\end{tabular}

for the patient portal. Only 109 (59\%) enrolled their newborn in the patient portal and were randomized into intervention and control groups (Fig. 1). While this sample size of 109 is less than the 130 used in the study sample size calculation, recruitment was stopped to allow for timely completion of the trial.

Among the randomized cohort, mothers had a mean (SD) maternal age of 29.2 (4.9) years, were predominantly White, non-Hispanic, and in a dual-parent household (Table 2). The majority were college educated, had private insurance, were breastfeeding, and had household incomes greater than $\$ 50,000$. Those mothers who enrolled, but did not fulfill criteria for randomization, namely did not enroll in the patient portal, were more likely to be racial/ethnic minorities, multiparous, single, Medicaid-insured, and smokers $(P<.10$ for each).

\section{Feasibility}

The effort required to enroll in the patient portal impeded randomization for the first 64 consenting participants. Mothers were required to undergo a timesensitive three-step process to enroll their newborn in the patient portal, resulting in only one-third of this first group of consenting mothers being randomized. For the final 66 participants, we successfully streamlined the patient portal enrollment process after working with those managing this process to create a patient portal registration form. By the end of the trial, among the final 66 participants, two-thirds enrolled in the patient portal and were randomized.

The second part of the feasibility assessment involved the submission of photographs per the study protocol. The 55 intervention group mothers were sent e-

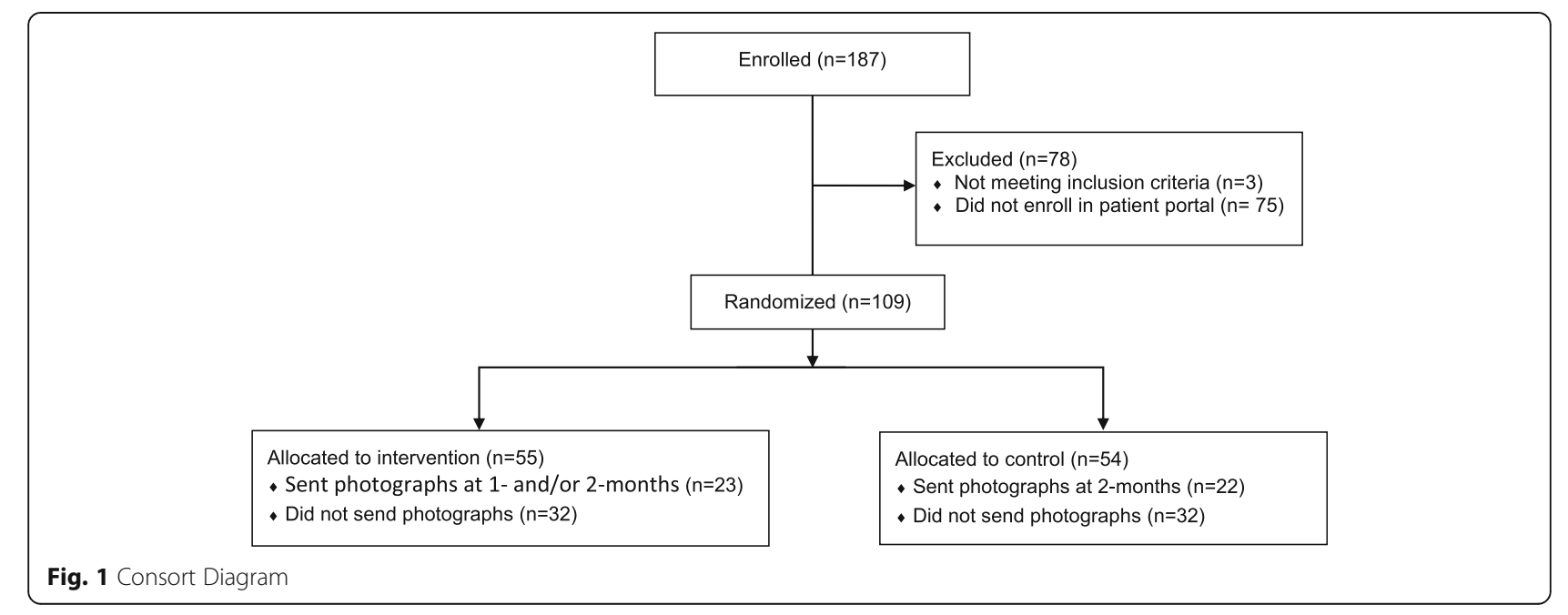


Table 2 Demographics of randomized cohort $(N=109)$

\begin{tabular}{|c|c|c|}
\hline & $\begin{array}{l}\text { Intervention } \\
(N=55)\end{array}$ & $\begin{array}{l}\text { Control } \\
(N=54) \\
\end{array}$ \\
\hline \multicolumn{3}{|l|}{ Infant characteristics } \\
\hline Female Sex, N (\%) & $27(49)$ & $28(52)$ \\
\hline $\begin{array}{l}\text { Gestational age in weeks, mean } \\
\text { (SD) }\end{array}$ & $39.4(1.1)$ & $39.4(1.2)$ \\
\hline Birth weight in kg, mean (SD) & $3.38(0.49)$ & $3.37(0.46)$ \\
\hline \multicolumn{3}{|l|}{ Feeding Mode, N (\%) } \\
\hline Exclusive Breast & $42(76)$ & $40(74)$ \\
\hline Exclusive Formula & $5(9)$ & $7(13)$ \\
\hline Combination & $8(15)$ & $7(13)$ \\
\hline \multicolumn{3}{|l|}{ Maternal characteristics } \\
\hline Mother's age, Mean (SD) & $28.9(4.0)$ & $29.4(5.7)$ \\
\hline \multicolumn{3}{|l|}{ Parity } \\
\hline 0 & $27(49)$ & $25(46)$ \\
\hline$\geq 1$ & $28(51)$ & $29(54)$ \\
\hline Smoke during pregnancy, $\mathrm{N}(\%)$ & $7(13)$ & $5(9)$ \\
\hline \multicolumn{3}{|l|}{ Mother's Race, N (\%) } \\
\hline Black & $4(7)$ & $4(7)$ \\
\hline White & $43(78)$ & $42(78)$ \\
\hline Asian & $4(7)$ & $6(11)$ \\
\hline Other & $4(8)$ & $2(4)$ \\
\hline Hispanic or Latino Ethnicity, N (\%) & $5(9)$ & $4(7)$ \\
\hline Married or Cohabitating, N (\%) & $50(91)$ & $45(83)$ \\
\hline \multicolumn{3}{|l|}{ Insurance, N (\%) } \\
\hline Private health insurance & $45(82)$ & $42(78)$ \\
\hline Medicaid & $10(18)$ & $10(19)$ \\
\hline Other & $0(0)$ & $2(4)$ \\
\hline \multicolumn{3}{|l|}{ Education, $\mathrm{N}(\%)$} \\
\hline High school graduate or less & $12(22)$ & $11(20)$ \\
\hline Some college or technical school & $15(27)$ & $13(24)$ \\
\hline Completed college & $28(51)$ & $30(56)$ \\
\hline
\end{tabular}

Plan to work outside the home in next 12 months, $\mathbf{N}(\%)$

$\begin{array}{lll}\text { Yes } & 42(76) & 39(72) \\ \text { No } & 10(18) & 10(19) \\ \text { Unsure } & 3(6) & 5(9) \\ \text { Number of people living in } & 2(1-3) & 2(1-3)\end{array}$

household, Median (IQR)

Household income, N (\%)

$<\$ 50,000$

$15(27) \quad 12(22)$

$\$ 50,000$ to $<\$ 100,000$

$\geq \$ 100,000$

18 (33)

$23(43)$

Do not know or Refuse to Answer

15 (27)

$13(24)$

$7(13)$

$6(11)$

Type of home, $\mathrm{N}(\%)$

single family

Multi-family
Table 2 Demographics of randomized cohort $(N=109)$

(Continued)

\begin{tabular}{lll}
\hline & $\begin{array}{l}\text { Intervention } \\
(\mathbf{N = 5 5 )}\end{array}$ & $\begin{array}{l}\text { Control } \\
(\mathbf{N = 5 4 )}\end{array}$ \\
\hline Apartment & $9(16)$ & $9(17)$ \\
Townhome & $10(18)$ & $10(19)$ \\
Mobile home or trailer & $1(2)$ & $1(2)$ \\
Other & $3(6)$ & $1(2)$ \\
\hline
\end{tabular}

messages at infant age 1 month with only 21 (38, 95\% CI 25-52\%) responding with photographs. At 2 months, 18 intervention group and 22 control group mothers sent photographs (37, 95\% CI 28-46\%). Following the first emessage by the study team, participants returned photographs through the patient portal at a median of $62 \mathrm{~h}$ (interquartile range (IQR) 37-70 h). The study team returned standardized feedback at a median of $24 \mathrm{~h}$ (IQR $13-51 \mathrm{~h})$.

\section{Efficacy \\ Photograph characteristics}

For the 55 participants in the intervention group, 32 (58\%) never sent a photograph at either time point, 5 (9\%) sent a photograph only at 1 month, 2 (4\%) sent a photograph only at 2 months, and 16 (29\%) sent a photograph at both time points. The response at 2 months was higher in the control group (41 to 33\%), but not statistically significant $(P=0.39)$. At infant age 1 month (intervention group), those sending photographs were more likely to have completed a college degree. At infant age 2 months, for the entire cohort, those sending photographs were more likely to be white and have completed a college degree.

At infant age 1 month, intervention group mothers sent a median of 2 photographs (range 1-4; Table 3). For these 21 infants, 7 (33\%) were not sleeping in a room with a caregiver, and the sleep location could not be determined in 3 (14\%). For the sleep surface, the photographs showed non-AAP guideline adherent sleeping arrangements including those sleeping on non-firm surfaces $(5 \%)$ and those with objects on their sleep surface (e.g. 10\% had loose bedding, 5\% had a facial covering). Accounting for all items on the checklist, $57 \%$ of intervention group infants met all safe sleep criteria at 1 month when including sleep location; 81\% met all safe sleep criteria excluding sleep location.

At 2 months, among those sending photographs $(N=$ 18 ), intervention group mothers sent a median of 2 (range 2-4). Sleep location (33\% not in parent's room), non-supine sleep (6\%), and objects on the sleep surface were identified in some photographs (e.g. $11 \%$ with loose bedding, $11 \%$ with bumper pads, and $6 \%$ with a sleep wedge/position). Control group mothers sent a median 
Table 3 Infant sleep photograph characteristics

\begin{tabular}{|c|c|c|c|}
\hline & $\begin{array}{l}\text { Intervention - Month } 1 \\
(N=21)\end{array}$ & $\begin{array}{l}\text { Intervention - Month } 2 \\
(N=18)\end{array}$ & $\begin{array}{l}\text { Control - Month } 2 \\
(N=22)\end{array}$ \\
\hline \multicolumn{4}{|l|}{ Number submitted } \\
\hline Median (Range) & $2(1-4)$ & $2(2-4)$ & $2(1-4)$ \\
\hline \multicolumn{4}{|l|}{ Sleep location, $\mathbf{N}(\%)$} \\
\hline Own room & $5(24)$ & $4(22)$ & $3(14)$ \\
\hline Parents' room & $11(52)$ & $7(39)$ & $16(73)$ \\
\hline Another room of the house & $1(5)$ & $2(11)$ & $2(9)$ \\
\hline Sibling's room & $1(5)$ & $0(0)$ & $0(0)$ \\
\hline Cannot be determined & $3(14)$ & $5(28)$ & $1(5)$ \\
\hline \multicolumn{4}{|l|}{ Outermost piece of clothing, $\mathrm{N}(\%)$} \\
\hline Shirt & $0(0)$ & $0(0)$ & $1(5)$ \\
\hline Shirt and pants & $1(5)$ & $1(6)$ & $0(0)$ \\
\hline Onesy & $1(5)$ & $2(11)$ & $5(23)$ \\
\hline Pajamas & $5(24)$ & $2(11)$ & $4(18)$ \\
\hline Swaddle blanket & $8(38)$ & $6(33)$ & $6(27)$ \\
\hline Sleep sack & $6(29)$ & $5(28)$ & $4(18)$ \\
\hline Other & $0(0)$ & $2(11)$ & $2(9)$ \\
\hline \multicolumn{4}{|l|}{ Sleep surface, N (\%) } \\
\hline Crib & $9(43)$ & $8(44)$ & $7(32)$ \\
\hline Bassinet & $5(24)$ & $5(28)$ & $10(45)$ \\
\hline Cradle & $0(0)$ & $1(6)$ & $1(5)$ \\
\hline Bedside co-sleeper ("sidecar") & $0(0)$ & $0(0)$ & $1(5)$ \\
\hline Co-sleeper in middle of bed & $0(0)$ & $0(0)$ & $1(5)$ \\
\hline Pac n Play, traveling bed, portable play yard & $5(24)$ & $4(22)$ & $1(5)$ \\
\hline Rock $n$ play & $1(5)$ & $0(0)$ & $1(5)$ \\
\hline Other & $1(5)$ & $0(0)$ & $0(0)$ \\
\hline \multicolumn{4}{|l|}{ Firm sleep surface, $\mathrm{N}(\%)$} \\
\hline Yes & $19(90)$ & $17(94)$ & $22(100)$ \\
\hline No & $1(5)$ & $0(0)$ & $0(0)$ \\
\hline Unsure & $1(5)$ & $1(6)$ & $0(0)$ \\
\hline \multicolumn{4}{|l|}{ Sleep position, $\mathrm{N}(\%)$} \\
\hline Supine (on back) & $21(100)$ & $17(94)$ & $21(96)$ \\
\hline Side & $0(0)$ & $1(6)$ & $1(5)$ \\
\hline \multicolumn{4}{|l|}{ Objects on sleep surface, $\mathrm{N}(\%)$} \\
\hline Yes (Infants with $\geq 1$ object) & $2(10)$ & $3(17)$ & $5(23)$ \\
\hline Pillow/cushion & $0(0)$ & $0(0)$ & $2(9)$ \\
\hline Stuffed animal/pillow like toy & $0(0)$ & $0(0)$ & $1(5)$ \\
\hline Loose bedding & $2(10)$ & $2(11)$ & $4(18)$ \\
\hline Bumper pads & $0(0)$ & $2(11)$ & $0(0)$ \\
\hline Sleep positioner/wedge & $0(0)$ & $1(6)$ & $2(9)$ \\
\hline Loose cord/electrical wire & $0(0)$ & $0(0)$ & $1(5)$ \\
\hline White Noise Machine & $0(0)$ & $0(0)$ & $2(9)$ \\
\hline Head covering, $\mathbf{N}(\%)$ & $1(5)$ & $1(6)$ & $0(0)$ \\
\hline Mobile/hanging toy within reach, $\mathrm{N}(\%)$ & $2(10)$ & $1(6)$ & $0(0)$ \\
\hline Sleep surface shared with another person, $\mathbf{N}(\%)$ & $0(0)$ & $0(0)$ & $1(5)$ \\
\hline Pacifier, N(\%) & $2(14)$ & $2(11)$ & $1(5)$ \\
\hline
\end{tabular}


of 2 photographs (range 1-4) at 2 months. For the 22 control infants with photographs, sleep location (23\% not sleeping in parent's room), bedsharing (5\%), unapproved sleep surfaces, and objects on the sleep surface were identified (e.g.18\% with loose bedding, 9\% with pillows/cushions, $9 \%$ with a sleep positioner/wedge).

Comparing study groups at 2 months revealed no significant differences in adherence to safe sleep guidelines. $55.6 \%$ of intervention group participants who submitted photographs met all safe sleep criteria compared with $45.4 \%$ of controls (difference of $0.10,95 \%$ CI -0.26 to $0.46, P=0.75)$ when sleep location was included. When excluding sleep location as a criteria, $83 \%$ of intervention group infants met all safe sleep criteria versus $68 \%$ of controls (difference of $0.15,95 \% \mathrm{CI}-0.16$ to $0.46, P=0.46$ ).

\section{Discussion}

While it is possible to use the EHR to promote personalized sleep recommendations based on photographs submitted by mothers through the patient portal, this trial encountered numerous barriers that must be overcome for this prevention strategy to be implemented in clinical care. Our finding that mothers who submitted photographs demonstrated a high rate of non-adherence to AAP guidelines emphasizes that efforts to prevent sleeprelated infant deaths must be enhanced, but the method we tested can only be used if enrollment in the patient portal is simple and mothers demonstrate a willingness to respond to prompts for photographs.

There have been few successful randomized clinical trials to improve infant safe sleep practices, but most focus on supine sleeping and bed sharing $[15,23,24]$. The rates of supine sleeping (95\%) and lack of bed sharing $(97.5 \%)$ attained in this study are much higher than have been attained in other studies, and demonstrate that those who sent photographs have sufficient knowledge about the importance of these two practices. In contrast, regarding adherence to the totality of the AAP guidelines, only $50 \%$ of participants met all safe sleep recommendations at age 2 months with no significant differences between study groups. This is disappointing as age 2 months is a time when cases of SUID are peaking and in need of innovative interventions to enhance preventive efforts as well as adherence to the AAP guidelines. Further, because the photographs are a glimpse at one point during an infant's sleep, it is uncertain the extent to which these already low percentages decrease over the course of the night. Our previous study found that infants that changed locations overnight typically were moved to a sleep environment with a greater number of risk factors for SUID [13].

Enrolling in the patient portal impeded randomization for some of the initial participants who consented for the trial. After simplification of the procedures required to enroll, we were able to improve newborn patient portal enrollment rates. Our experience suggests a streamlined patient portal registration process can improve patient portal registration among patients and increase utilization. Additionally, efforts aimed at decreasing barriers for mothers with fewer resources and more barriers may need extra considerations to promote utilization.

Participant photograph submission rates were also lower than expected suggesting additional barriers to our approach. We have several hypotheses for this observation. The first 2 months of an infant's life require extensive time from mothers, and communicating with a research team through a patient portal may not have been a priority. It is possible that rates may have been improved had such communication been initiated by primary care providers. Next, the patient portal user interface may not be user friendly and make it more difficult for mothers to abide to the study protocol. Another possibility is that online patient portals are still not widely used and accepted by our population, which is supported by several studies analyzing patient portal usage in the United States $[17,18]$.

We offer several suggestions to improve patient portal use in the clinical realm and studies with newborns. Enrolling newborns before discharge from the hospital or creating a more streamlined enrollment process would likely improve patient portal registration rates. We also suggest efforts must be made to ensure that the patient portal is user friendly, usable by those with low health literacy, and fully smartphone compatible. Despite the challenges we encountered, we encourage future efforts to assess whether patient portals can be used to individualize safe infant sleep care particularly once patients become more accustomed to this technology. Efforts to study differences in patient portal usage among parents of newborns may provide further insight into improving patient portal access and use among this population.

We acknowledge the limitations of this study. Our sample size was lower than anticipated, which results in lower power for our hypothesized effect size. Of those randomized, our cohort was largely non-Hispanic, White, and college educated, with a low proportion of low-income families. Thus, our results may not be generalizable to other demographic groups, and are not generalizable to those patients at highest risk of SUID. Furthermore, participants from lower socioeconomic backgrounds may have a more difficult time accessing internet services, despite indicating that they had full access to internet when enrolling. The lack of photographs with bedsharing may indicate parental unwillingness to share this particular infant care practice or simply the above-mentioned limited statistical power of the study. Lastly, though the presence of wedges underneath or 
above the mattress was part of the review process, we could not fully assess whether infants were positioned in an inclined versus supine sleep position, as the latter is advised by the AAP.

The current study also occurred within a single health system in Pennsylvania. Given that there are specific state laws for SUID education for parents prior to leaving the hospital, our findings may not be generalizable to other health systems within and outside of Pennsylvania. Parents were aware that their photographs were to be analyzed for safe infant sleep. Thus, it is possible that we may have underestimated the numbers of newborns who were placed in unsafe sleep environments. Nonetheless, our results suggest that parents who sent in photographs demonstrated significant non-adherence to safe infant sleep recommendations.

\section{Conclusion}

Utilizing the EHR to personalize infant sleep recommendations based on photographs submitted by mothers through patient portals is possible, however, we encountered several barriers, including poor patient portal registration and poor response to requests for photographs at study time points. Submitted photographs of infants aged 1-2 months old demonstrated substantial non-adherence to AAP guidelines. Further research is indicated to determine if using the EHR to promote personalized infant sleep safety is effective, and what types of education and interventions are effective at improving safe infant sleep.

\begin{abstract}
Abbreviations
EHR: Electronic health record; AAP: American Academy of Pediatrics; SUID: Sudden Unexpected Infant Death; SIDS: Sudden Infant Death Syndrome; IQR: Interquartile range
\end{abstract}

\section{Acknowledgements}

Not applicable.

\section{Authors' contributions}

EC - assisted in designing the study, led recruitment of study participants, drafted the manuscript, and read and approved the manuscript. BF - assisted in designing the study, assisted with technical aspects of the trial, participated in manuscript revision, and read and approved the manuscript. EB - assisted in designing the study, assisted with technical aspects of the trial, participated in manuscript revision, and read and approved the manuscript. ES - assisted in designing the study, assisted with technical aspects of the trial, assisted with data analysis, participated in manuscript revision, and read and approved the manuscript. JB - assisted in designing the study, assisted with technical aspects of the trial and participant recruitment, participated in manuscript revision, and read and approved the manuscript. IP - led the design of the trial, assisted with technical aspects of the trial, participated in the manuscript revision, and read and approved the manuscript.

\section{Funding}

Research was supported by the Ashley Nicole Shellenberger SIDS Research Fund at the Penn State College of Medicine. Research reported in this publication was also supported by the National Center for Advancing Translational Sciences, NIH Grants TL1 TR002016 and UL1 TR002014. The content is solely the responsibility of the authors and does not necessarily represent the official views of the $\mathrm{NIH}$. The funding sources were not involved in the study design, collection, analysis and interpretation of data, writing of the report, or in the decision to submit the article for publication.

\section{Availability of data and materials}

The datasets generated and/or analyzed during the current study are not publicly available due to photographs being submitted through the electronic health record, which are not sharable. However, the remainder of the study data are available from the corresponding author on reasonable request.

\section{Ethics approval and consent to participate}

The Human Subjects Protection Office of the Penn State College of Medicine approved this study and it was registered at http://www.clinicaltrials.gov prior to first participant's enrollment (NCT03662048). All participants signed informed consent documents prior to their participation in the trial.

\section{Consent for publication}

Not applicable.

\section{Competing interests}

The authors have no conflicts of interest relevant to this article to disclose. The authors have no financial relationships relevant to this article to disclose.

\section{Author details}

${ }^{1}$ Department of Pediatrics, Oregon Health \& Science University, Portland, OR, USA. 'Department of Pediatrics, Penn State College of Medicine, HS83, 500 University Drive, Hershey, PA 17033, USA. ${ }^{3}$ Family and Community Medicine, Penn State College of Medicine, Hershey, PA, USA. ${ }^{4}$ Public Health Sciences, Penn State College of Medicine, Hershey, PA, USA.

Received: 16 June 2020 Accepted: 30 September 2020

Published online: 08 October 2020

\section{References}

1. Goldstein RD, Trachtenberg FL, Sens MA, Harty BJ, Kinney HC. Overall postneonatal mortality and rates of SIDS. Pediatrics. 2016;137(1). https://doi. org/10.1542/peds.2015-2298.

2. Centers for Disease Control. Linked birth/infant death records on CDC WONDER online database. Available from: https://wonder.cdc.gov/lbd.html. Accessed 29 June 2020.

3. Shapiro-Mendoza CK, Tomashek KM, Anderson RN, Wingo J. Recent national trends in sudden, unexpected infant deaths: more evidence supporting a change in classification or reporting. Am J Epidemiol. 2006;163(8):762-9.

4. Carlin RF, Moon RY. Risk factors, protective factors, and current recommendations to reduce sudden infant death syndrome a review. JAMA Pediatr. 2017;171(2):175-80.

5. Moon RY. SIDS and other sleep-related infant deaths: updated 2016 recommendations for a safe infant sleeping environment. Pediatrics. 2016; 138(5):e20162940 Available from: http://pediatrics.aappublications.org/cgi/ doi/10.1542/peds.2016-2940.

6. Moon RY. SIDS and other sleep-related infant deaths: evidence base for 2016 updated recommendations for a safe infant sleeping environment. Pediatrics. 2016;138(5):e20162940 Available from: http://pediatrics. aappublications.org/cgi/doi/10.1542/peds.2016-2940.

7. Zundo K, Richards EA, Ahmed AH, Codington JA. Factors associated with parental compliance with supine infant sleep: an integrative review. Pediatr Nurs. 2017:43(2):83-91

8. Colson ER, Levenson S, Rybin D, Calianos C, Margolis A, Colton T, et al. Barriers to following the supine sleep recommendation among mothers at four centers for the women, infants, and children program. Pediatrics. 2006; 118(2):e243-50.

9. Smylie J, Fell DB, Chalmers B, Sauve R, Royle C, Allan B, et al. Socioeconomic position and factors associated with use of a nonsupine infant sleep position: findings from the Canadian maternity experiences survey. Am J Public Health. 2014:104(3):539-47.

10. Gaydos LM, Blake SC, Gazmararian JA, Woodruff W, Thompson WW, Dalmida SG. Revisiting safe sleep recommendations for African-American infants: why current counseling is insufficient. Matern Child Health J. 2015 19(3):496-503.

11. Barnes-Josiah DL, Eurek P, Huffman S, Heusinkvelt J, Severe-Oforah J, Schwalberg R. Effect of "this side up" T-shirts on infant sleep position. Matern Child Health J. 2007;11(1):45-8. 
12. Moon RY, Oden RP, Grady KC. Back to sleep: an educational intervention with women, infants, and children program clients. Pediatrics. 2004;113(3 Pt 1):542-7.

13. Batra EK, Teti DM, Schaefer EW, Neumann BA, Meek EA, Paul IM. Nocturnal video assessment of infant sleep environments. Pediatrics. 2016;138(3): e20161533 Available from: http://pediatrics.aappublications.org/cgi/doi/1 0.1542/peds.2016-1533.

14. Cole R, Young J, Kearney L, Thompson JMD. Infant care practices and parent uptake of sleep messages: a cross-sectional survey of infant care practices in Queensland, Australia. BMC Pediatrics. 2020;20:27.

15. Moon RY, Hauck FR, Colson ER, Kellams AL, Geller NL, Heeren T, et al. The effect of nursing quality improvement and mobile health interventions on infant sleep practices: a randomized clinical trial. JAMA. 2017;318(4):351-9.

16. Mathews A, Joyner BL, Oden RP, He J, McCarter R, Moon RY. Messaging affects the behavior of African American parents with regards to soft bedding in the infant sleep environment: a randomized controlled trial. J Pediatr. 2016;175:79-85.e2. https://doi.org/10.1016/j.jpeds.2016.05.004.

17. States U, Accountability G. Health Information Technology: HHS Should Assess the Effectiveness of Its Efforts to Enhance Patient Access to and Use of Electronic Health Information What GAO Found. 2017. Available from: https://www.gao.gov/assets/690/683789.pdf. Accessed 29 June 2020.

18. Anthony DL, Campos-Castillo C, Lim PS. Who isn't using patient portals and why? Evidence and implications from a national sample of US adults. Health Aff. 2018;37(12):1948-54 Available from: http://www.healthaffairs.org/doi/1 $0.1377 /$ hlthaff.2018.05117.

19. Kummerow Broman K, Oyefule OO, Phillips SE, Baucom RB, Holzman MD, Sharp KW, et al. Postoperative care using a secure online patient portal: changing the (inter) face of general surgery. J Am Coll Surg. 2015;221(6): 1057-66.

20. Otte-Trojel T, de Bont A, Rundall TG, van de Klundert J. How outcomes are achieved through patient portals: a realist review. J Am Med Inform Assoc. 2014;21(4):751-7.

21. Krist AH, Woolf SH, Rothemich SF, Johnson RE, Peele JE, Cunningham TD, et al. Interactive preventive health record to enhance delivery of recommended care: a randomized trial. Ann Fam Med. 2012;10(4):312-9.

22. Sudden Infant Death Syndrome Education and Prevention Program Act. 73 United States of America: Pennsylvania Department of Health; 2010. Available from: https://www.health.pa.gov/topics/Documents/Laws\%2 Oand\%20Regulations/SIDS\%20Act.pdf.

23. Moon RY, Calabrese T, Aird L. Reducing the risk of sudden infant death syndrome in child care and changing provider practices: lessons learned from a demonstration project. Pediatrics. 2008;122(4):788-98 Available from: http://pediatrics.aappublications.org/cgi/doi/10.1542/peds.2007-3010.

24. Issler RMS, Marostica PJC, Giugliani ERJ. Infant sleep position: a randomized clinical trial of an educational intervention in the maternity ward in Porto Alegre, Brazil. Birth. 2009;36(2):115-21.

\section{Publisher's Note}

Springer Nature remains neutral with regard to jurisdictional claims in published maps and institutional affiliations.

\section{Ready to submit your research? Choose BMC and benefit from:}

- fast, convenient online submission

- thorough peer review by experienced researchers in your field

- rapid publication on acceptance

- support for research data, including large and complex data types

- gold Open Access which fosters wider collaboration and increased citations

- maximum visibility for your research: over $100 \mathrm{M}$ website views per year

At $\mathrm{BMC}$, research is always in progress.

Learn more biomedcentral.com/submissions 